\title{
Code Development in Coupled PARCS/RELAP5 for Supercritical Water Reactor
}

\author{
Po Hu${ }^{1}$ and Paul Wilson ${ }^{2}$ \\ ${ }^{1}$ School of Nuclear Science and Engineering, Shanghai Jiao Tong University, Shanghai 200240, China \\ ${ }^{2}$ Department of Engineering Physics, University of Wisconsin-Madison, Madison, WI 53705, USA
}

Correspondence should be addressed to Po Hu; pohu@sjtu.edu.cn

Received 6 January 2014; Revised 9 April 2014; Accepted 10 April 2014; Published 8 May 2014

Academic Editor: Jiejin Cai

Copyright (c) 2014 P. Hu and P. Wilson. This is an open access article distributed under the Creative Commons Attribution License, which permits unrestricted use, distribution, and reproduction in any medium, provided the original work is properly cited.

\begin{abstract}
The new capability is added to the existing coupled code package PARCS/RELAP5, in order to analyze SCWR design under supercritical pressure with the separated water coolant and moderator channels. This expansion is carried out on both codes. In PARCS, modification is focused on extending the water property tables to supercritical pressure, modifying the variable mapping input file and related code module for processing thermal-hydraulic information from separated coolant/moderator channels, and modifying neutronics feedback module to deal with the separated coolant/moderator channels. In RELAP5, modification is focused on incorporating more accurate water properties near SCWR operation/transient pressure and temperature in the code. Confirming tests of the modifications is presented and the major analyzing results from the extended codes package are summarized.
\end{abstract}

\section{Introduction}

The supercritical water reactor (SCWR) is a generation IV nuclear reactor concept characterized by its system simplification and high thermal efficiency. Due to its higher operating pressure and temperature, separated moderator and coolant channels, and a strong coupling between power (neutronics calculation) and moderator temperature (thermalhydraulic $(\mathrm{T} / \mathrm{H})$ calculation) because of a large density variation of water $\left(100\right.$ to $\left.700 \mathrm{~kg} / \mathrm{m}^{3}\right)$, existing LWR codes are not capable of analyzing SCWR design without appropriate modifications [1]. Yamaji et al. have shown coupled neutronics and $\mathrm{T} / \mathrm{H}$ analysis of high temperature supercriticalpressure light water reactor (SCLWR-H). The code package includes SRAC code system (neutronics) from Japan Atomic Energy Research Institute (JAERI) and SPROD code (T/H) from University of Tokyo. Buongiorno and Macdonald presented and analyzed the U.S. reference SCWR design using RELAP5 with a point kinetics model $[2,3]$. The current study developed a neutronics and $\mathrm{T} / \mathrm{H}$ coupled analysis capability for the U.S. reference design by extending existing LWR analysis code package, that is, the core simulator PARCS and the T/H code RELAP5, which have been verified for analyzing PWR and BWR in coupled mode and are easily accessible for academic purposes [4]; this paper discusses the codes modifications and presents the preliminary tests confirming the major extensions in code coupling module and nuclear cross section feedback module in PARCS and water property module in RELAP5. The SCWR analyzing results using the extended code package are summarized here and the details are discussed in another paper [5].

\section{Existing Coupling Mechanism}

Current study analyzes the SCWR using extended code package PARCS/RELAP5.

PARCS [6] is a 3D reactor core simulator developed in Purdue University. It solves the steady state, time-dependent, and multigroup neutron diffusion equation and SP3 transport equation to predict the dynamic response of the reactor to reactivity perturbations. PARCS is applicable to both PWR and BWR and can be coupled directly to the $\mathrm{T} / \mathrm{H}$ system code RELAP5.

RELAP5 [7] is a T/H code designed for best-estimate transient simulation of light water reactor system. It was developed at the Idaho National Lab for the U.S. Nuclear Regulatory Commission. It is capable of modeling coupled 


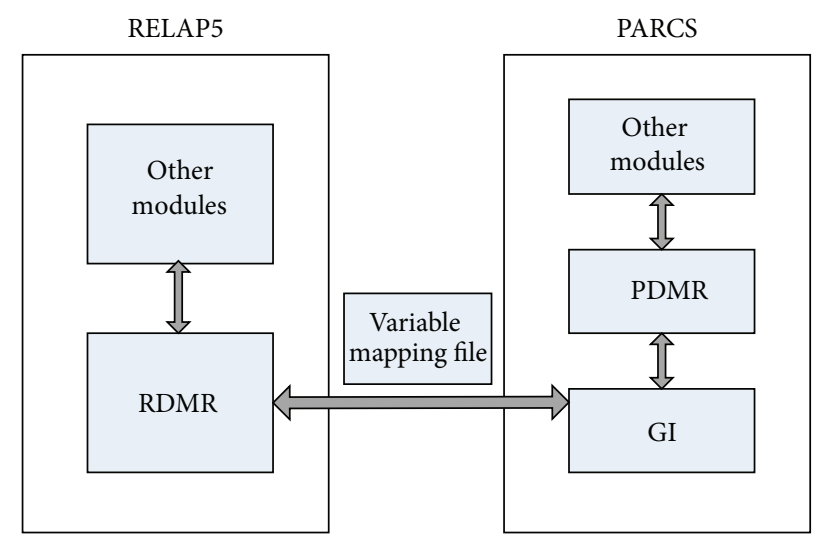

FIgURE 1: PARCS/RELAP5 coupling mechanism.

behavior of the reactor coolant system and core for accidents and transients using eight field equations. The version used in current study is RELAP5/MOD3.3.

In order to simulate the feedback between the thermalhydraulics and the neutronics, the field equations of RELAP5 can be coupled to either a built-in point kinetics model or a 3D neutronics code PARCS. By using the 3D kinetics code we can calculate power distribution in a new type of reactor design such as SCWR instead of appealing to typical LWR parameters like in point kinetics model.

To couple PARCS/RELAP5, in the point of view of PARCS, is to replace the internal thermal hydraulics solver in PARCS with an external T/H code, which is RELAP5 in this case (Figure 1). As the solving scheme of a steady state problem shown in Figure 2, PARCS performs neutronics calculation to generate new power profile with nuclear cross section information based on the temperature data from RELAP5; then RELAP5 receives the updated power profile from PARCS and performs $\mathrm{T} / \mathrm{H}$ calculations to generate the new temperatures of fuel, moderator, and coolant and passes the temperature information back to PARCS. The coupled simulation will be ended when the iteration in PARCS converges.

The RELAP5 data map routine (RDMR) module in RELAP5 is designed to communicate with neutronics code PARCS through a general interface (GI) module in PARCS. The PARCS-specific data map routine (PDMR) module in PARCS is the counterpart to RDMR in RELAP5, and it functions as an interface between PARCS and external T/H codes, such as RELAP5 and TRAC-M, through the GI module. PDMR is designed to maintain consistency with the requirements of both the GI and the RDMR while preparing data to be transferred to RELAP5. A space-dependent variable mapping input file read by PDMR module defines the corresponding nodes between PARCS and RELAP5 models. The parallel virtual machine (PVM) code is utilized to control the communications between two codes.

The U.S. reference design is essentially a light water reactor (LWR) operating at higher pressure and temperature with a direct cycle. Comparing to a normal PWR, the major difference is that SCWR uses light water as moderator and

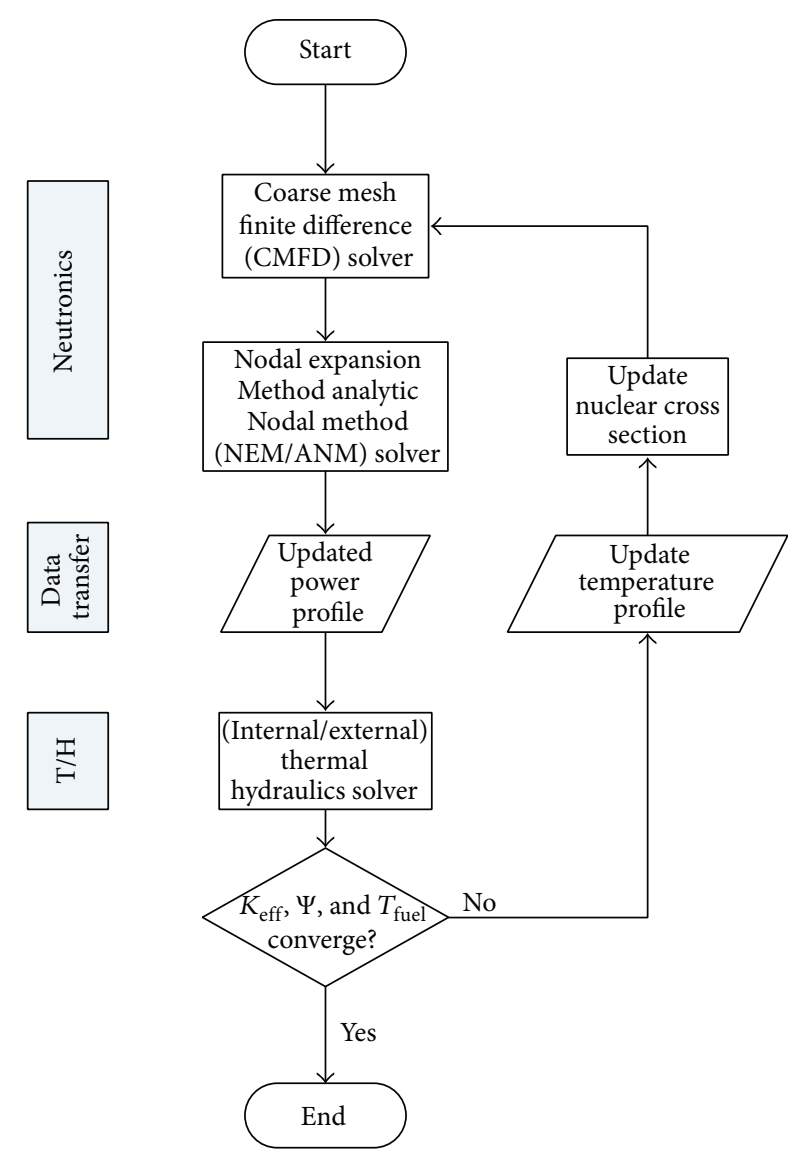

FIGURE 2: Solving scheme for steady state eigenvalue problem in PARCS.

coolant in separated channels as shown in Figure 3; the feed water temperature is $280^{\circ} \mathrm{C}$ and outlet temperature is $500^{\circ} \mathrm{C}$ at pressure of $25 \mathrm{MPa}[2,3]$.

\section{Modifications on PARCS}

Because the SCWR reference design has higher operating pressure and temperature and utilizes the new cladding material and separated coolant and moderator channels [8], in order to analyze it the following modules in PARCS need to be modified:

(i) water and cladding thermophysical property functions or tables are modified accordingly;

(ii) variable mapping input file and PDMR module need to be modified to deal with information from extra flow channel, in order to model separated coolant and moderator flow channels;

(iii) the nuclear macroscopic cross section updating module in PARCS should be extended to include the feedback based on not only fuel and coolant but also moderator thermophysical properties; the accessory modification in PARCS also includes the new input lines for SCWR specially in the input files and the new variable storage file for SCWR problem in source files. 


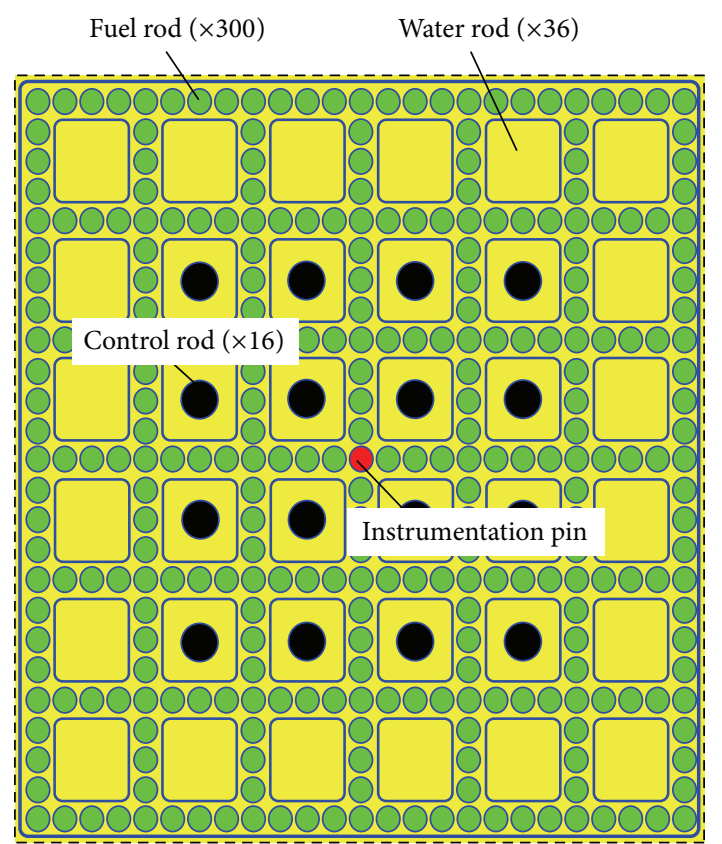

FIGURE 3: The cross sections assembly of U.S. reference design [2].

\subsection{Modification of Thermophysical Properties of Water and} Cladding. In coupled simulation mode (PARCS/RELAP5), the thermophysical properties will be supplied by $\mathrm{T} / \mathrm{H}$ solver RELAP5; however, in the initialization process in PARCS the functions describing thermophysical properties of water and cladding material functions are still called. Therefore the modifications in these functions are needed for SCWR analysis.

The thermophysical properties of water are originally described by simple polynomial equations as a function of temperature or enthalpy under PWR or BWR operating pressure. Therefore a water density function under supercritical pressure is added. Because of the dramatically changing water density near the pseudocritical point, a more sophisticated scheme specifying water density under $25 \mathrm{MPa}$ based on NBS/NRC steam tables [9] is adopted using lookup tables and data are arranged in uniform intervals of temperature $(0.1 \mathrm{~K})$ or enthalpy $(1 \mathrm{KJ} / \mathrm{Kg})$ and can be searched by direct index.

Because MA956 is used as cladding material in SCWR reference design instead of zircalloy for ordinary PWRs or BWRs in original PARCS, the polynomial functions of the conductivity and thermal capacity of MA956 based on tabulated data are implemented in the code for SCWR design [10].

\subsection{Modification in Nuclear Cross Section Feedback Module.} SCWR reference design has separated coolant and moderator channels, so water flowing in the separated channels has different temperatures and densities. Therefore the neutronics cross section feedback mechanism in PARCS should be able to handle the moderator and coolant themophysical properties separately.
The original PARCS can update the macroscopic cross section based on fuel temperature, coolant temperature, control rod positions, and burnable poison concentration, and the modified PARCS can also update the cross section based on moderator density and temperature. As shown in (1) underlined parameters are newly added, term $\left(\partial \Sigma / \partial T_{m}\right) \Delta T_{m}$ represents the cross section feedback due to the moderator temperature change, and term $\left(\partial \Sigma / \partial D_{m}\right) \Delta D_{m}+$ $\left(\partial^{2} \Sigma / \partial D_{m}^{2}\right)\left(\Delta D_{m}\right)^{2}$ represents cross section feedback due to the moderator density change; notice that the dependence of moderator temperature is modeled as linear, and dependence of moderator density is quadratic. There are two parts involved in the modification: firstly a new option is added into cross section feedback module in PARCS; secondly the cross section data file is updated to store the cross section information from different combinations of moderator and coolant themophysical properties, fuel temperature, and control rod position; the data file is generated using GenPMAXS code based on calculation results from lattice code HELIOS [11]:

$$
\begin{aligned}
\Sigma\left(\alpha, T_{f}, \underline{T_{m}}, T_{c}, \underline{D_{m}}, D_{c}\right)= & \Sigma_{r}+\alpha \Delta \Sigma_{c r}+\frac{\partial \Sigma}{\partial \sqrt{T_{f}}} \Delta \sqrt{T_{f}} \\
& +\frac{\partial \Sigma}{\frac{\partial T_{m}}{} \Delta T_{m}}+\frac{\partial \Sigma}{\partial T_{c}} \Delta T_{c} \\
& +\frac{\partial \Sigma}{\frac{\partial D_{m}}{} \Delta D_{m}+\frac{\partial^{2} \Sigma}{\partial D_{m}^{2}}\left(\Delta D_{m}\right)^{2}} \\
& +\frac{\partial \Sigma}{\partial D_{c}} \Delta D_{c}+\frac{\partial^{2} \Sigma}{\partial D_{c}^{2}}\left(\Delta D_{c}\right)^{2} .
\end{aligned}
$$

3.3. Modifications in Variable Mapping File and Coupling Module. PARCS is coupled to RELAP5 using PDMR module based on mapping rules defined in the space-dependent variable mapping input file. Because the SCWR reference design has separated moderator and coolant channels, extended mapping rules should be supplied in the variable mapping input file and corresponding modifications are needed in both PARCS and RELAP5.

As shown in Table 1, an original mapping input file contains four cards: "Trip," "DOPL," "Table 1," and "Table 2." The "Table 1" card defines the mapping rule between hydrodynamic volumes in RELAP5 model and neutronics nodes in PARCS model. "Table 2" card defines the mapping rule between heat structures in RELAP5 model and neutronics nodes in PARCS model. These two cards have multiple input lines in the same format.

In some cases the number of neutronics nodes in PARCS and the number of hydrodynamic volumes/structures in RELAP5 used to represent same physical region are different. The weighting factors are used to lump adjacent nodes or volumes/structures to make the mapping possible.

These mapping tables are sufficient for ordinary PWR/BWR designs, but not for the current SCWR design. The separation of moderator and coolant in SCWR instead of 
TABLE 1: PARCS/RELAP5 mapping input file.

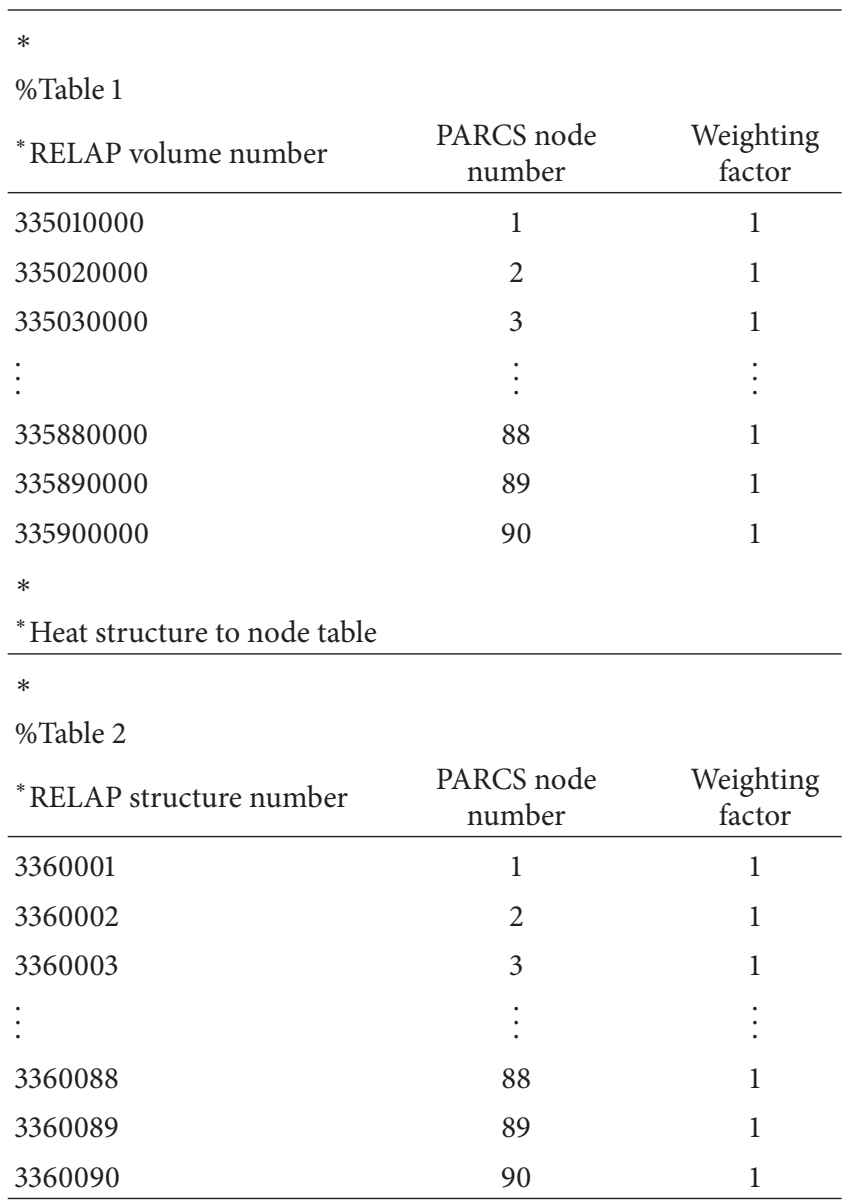

*Data ignored from the original table. And the ":” means the more similar input lines are ignored.

the combined moderator/coolant flow in PWR/BWR means for each neutronics node in SCWR PARCS model, there will be two corresponding hydrodynamic volumes in RELAP5: one representing coolant flow and the other moderator flow. Using the tables described above only one hydrodynamic volume can be matched to each neutronics node.

Therefore both the variable mapping file and related subroutines in PDMR module in PARCS are extended to solve this problem. In the new mapping input file, a fifth card, "Table 3," is added to map hydrodynamic volumes representing moderator flow to neutronics nodes. The original "Table 1" card now only manages the mapping between hydrodynamic volumes representing coolant flow and neutronics nodes.

Appropriate modifications in PDMA module are introduced to receive data from the newly added mapping table "Table 3" and integrate these data to a permutated matrix together with the mapping information from "Table 1 " and "Table 2" then send the matrix to RELAP5 together with the newly added control options for SCWR simulation in coupled mode. And the error checking subroutine is also updated for new mapping table "Table 3 " and moderator thermal properties.

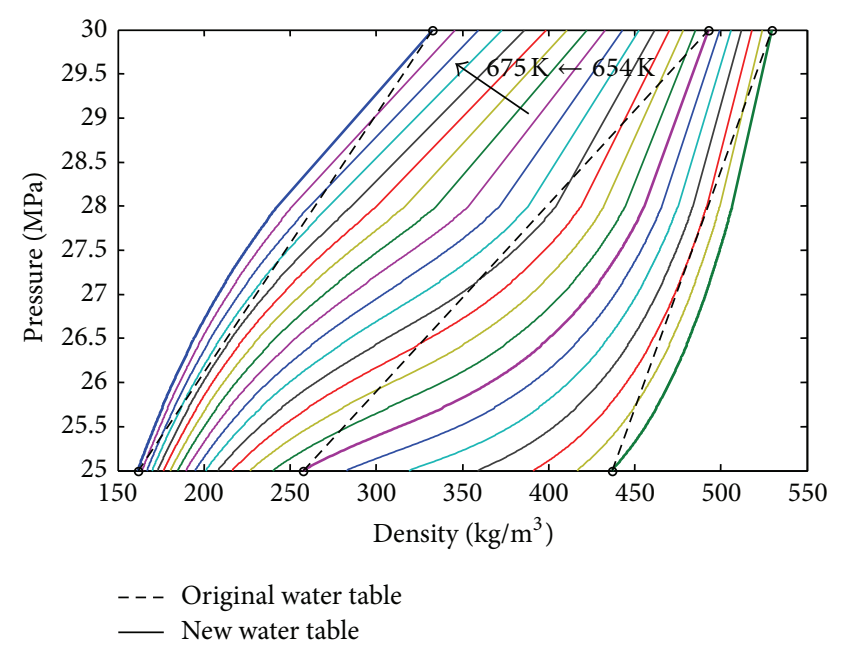

FIGURE 4: Density versus pressure in isotherm from original and modified water tables of RELAP5.

\section{Modification on RELAP5}

There are two modifications needed in the current version of RELAP5/MOD3.3 in the point of view of analyzing SCWR: RELAP5 is not stable at pressure above $25.9 \mathrm{MPa}$ where the SCWR transients usually happen, because a coarse grid in supercritical point region is used in water property table; the error checking routine in the module RDMR (RELAP data mapping routines) in RELAP5 treats the water density below $0.35 \mathrm{~g} / \mathrm{cm}^{3}$ as an error, but the water density can reach $0.1 \mathrm{~g} / \mathrm{cm}^{3}$ crossing pseudocritical point in SCWR.

4.1. Modification in Water Property Table. In RELAP5, the grid of the water property table is calculated by input temperature and pressure values. The original temperature values consist of 157 points with 15 points covering the supercritical temperature range $645 \mathrm{~K}-675 \mathrm{~K}$ and 14 points covering the higher temperature region $(700 \mathrm{~K}-6000 \mathrm{~K})$, and the pressure values consist of 116 points with 10 points covering the pressure range from 20.9 MPa to $30.0 \mathrm{MPa}$ and 5 points covering higher pressure region (30.0 $\mathrm{MPa}-99.9 \mathrm{MPa})$.

The modified input file increases the number of the points in the same ranges for both temperature ( $645 \mathrm{~K}-675 \mathrm{~K})$ and pressure (20.9 $\mathrm{MPa}-30.0 \mathrm{MPa}$ ); now in new temperature set there are 184 points with 37 points covering the range, and the increment is one degree among most points; in the new pressure set there are 578 points with 468 points covering the range. To accommodate these densifications, the corresponding variable arrays are expanded accordingly.

The improvement from this modification can be illustrated in Figure 4, in which the pressure-density correlations in isotherms $(P(D, T))$ are shown. The original water table uses only two pressure points $(25 \mathrm{MPa}$ and $30 \mathrm{MPa})$ and three temperature points $(654 \mathrm{~K}, 660 \mathrm{~K}, 675 \mathrm{~K})$ to represent the region in the plot, while the new water table uses 301 pressure points and 22 using interpolation; three straightline isotherms are used in original water table but 22 curved isotherms are used in new water table. After the modification, 
TABLE 2: SCWR parameters.

\begin{tabular}{|c|c|c|c|}
\hline \multicolumn{2}{|l|}{ Fuel Pin } & \multicolumn{2}{|c|}{ Fuel assembly } \\
\hline Fuel material & $\mathrm{UO}_{2}$ & Number of fuel rods & 240 \\
\hline Fissile enrichment & $5 \%$ & Number of burnable absorber & 60 \\
\hline $\mathrm{UO}_{2}$ density & $10.4215 \mathrm{~g} / \mathrm{cm}^{3}$ & Number of water rods & 36 \\
\hline Fuel radius & $0.439 \mathrm{~cm}$ & Number of control rods & 12 \\
\hline Pellet to cladding gap & $0.008 \mathrm{~cm}$ & Water rod width & $3.36 \mathrm{~cm}$ \\
\hline Cladding thickness & $0.063 \mathrm{~cm}$ & Water rod wall thickness & $0.04 \mathrm{~cm}$ \\
\hline Fuel pitch & $1.12 \mathrm{~cm}$ & Fuel assembly pitch & $28.82 \mathrm{~cm}$ \\
\hline$P / D$ & 1.098 & Assembly wall thickness & $0.3 \mathrm{~cm}$ \\
\hline Cladding and core structure material & MA956 & Interassembly gap & $0.2 \mathrm{~cm}$ \\
\hline \multicolumn{2}{|l|}{$\begin{array}{rr}\text { Burnable absorber } \\
\end{array}$} & \multicolumn{2}{|c|}{ Core } \\
\hline Burnable absorber material & $\mathrm{ZrB}_{2}$ & Thermal power & $3575 \mathrm{MW}$ \\
\hline $\mathrm{ZrB}_{2}$ density & $6.08 \mathrm{~g} / \mathrm{cm}^{3}$ & Number of fuel assemblies & 145 \\
\hline Fuel material & $\mathrm{UO}_{2}$ & Heated fuel height & $4.27 \mathrm{~m}$ \\
\hline Fissile enrichment & $5 \%$ & Total fuel pin height & $4.87 \mathrm{~m}$ \\
\hline $\mathrm{UO}_{2}$ density & $10.4215 \mathrm{~g} / \mathrm{cm}^{3}$ & Effective diameter & $3.93 \mathrm{~m}$ \\
\hline Fuel radius & $0.439 \mathrm{~cm}$ & Volumetric power density & $69 \mathrm{MW} / \mathrm{m}^{3}$ \\
\hline BA cover thickness & $0.0044 \mathrm{~cm}$ & Average linear heat rate & $19.2 \mathrm{~kW} / \mathrm{m}$ \\
\hline Pellet to cladding gap & $0.0036 \mathrm{~cm}$ & Fuel depletion plan & 3 cycles \\
\hline Cladding thickness & $0.063 \mathrm{~cm}$ & Average burnup & 0/12.5/25 GWd/MTU \\
\hline \multicolumn{2}{|l|}{ Control rod } & \multicolumn{2}{|c|}{ Thermal-hydraulic parameters } \\
\hline Control rod material & $\mathrm{B}_{4} \mathrm{C}$ & System pressure & $25 \mathrm{MPa}$ \\
\hline $\mathrm{B}_{4} \mathrm{C}$ density & $2.59 \mathrm{~g} / \mathrm{cm}^{3}$ & Coolant flow rate & $1843 \mathrm{~kg} / \mathrm{s}$ \\
\hline Control rod radius & $0.662 \mathrm{~cm}$ & Bypass ratio, $\eta$ & $10 \%(184 \mathrm{~kg} / \mathrm{s})$ \\
\hline Control rod guide tube inner radius & $0.912 \mathrm{~cm}$ & RPV inlet temperature & $280^{\circ} \mathrm{C}$ \\
\hline \multirow[t]{2}{*}{ Control rod guide tube thickness } & $0.04 \mathrm{~cm}$ & RPV outlet temperature & $500^{\circ} \mathrm{C}$ \\
\hline & & Thermal efficiency & $44.80 \%$ \\
\hline
\end{tabular}

TABLE 3: Temperatures and densities of moderator and coolant.

\begin{tabular}{lcccc}
\hline \multirow{2}{*}{ Node number } & \multicolumn{2}{c}{ Moderator } & \multicolumn{2}{c}{ Coolant } \\
\hline 1 & Temperature $\left({ }^{\circ} \mathrm{C}\right)$ & Density $\left(\mathrm{kg} / \mathrm{m}^{3}\right)$ & Temperature $\left({ }^{\circ} \mathrm{C}\right)$ & \multicolumn{1}{c}{ Density $\left(\mathrm{kg} / \mathrm{m}^{3}\right)$} \\
2 & 353.8 & 612.9 & 354.1 & 511.6 \\
3 & 353.7 & 613.1 & 372.8 & 419.3 \\
4 & 352.4 & 617.7 & 384.8 & 324.8 \\
5 & 350.1 & 625.1 & 387.1 & 255.4 \\
6 & 347.4 & 633.7 & 391.5 & 164.8 \\
7 & 344.3 & 643.1 & 399.5 & 141.6 \\
8 & 340.5 & 653.7 & 412.6 & 121.6 \\
9 & 335.9 & 666.2 & 431.2 & 106.5 \\
10 & 329.9 & 680.9 & 455.2 & 95.8 \\
11 & 322.0 & 699.1 & 481.0 & 92.7 \\
12 & 311.2 & 721.8 & 490.4 & \\
\hline
\end{tabular}

RELAP5/Mod3.3 can calculate the water properties under pressure up to $30 \mathrm{MPa}$ without large error as in original water table.

4.2. Modification in Error Checking Routines. Originally RDMR checks if the water density is between $1050 \mathrm{~kg} / \mathrm{m}^{3}$ and $305 \mathrm{~kg} / \mathrm{m}^{3}$, and this checking range is expanded to between
$1050 \mathrm{~kg} / \mathrm{m}^{3}$ and $5 \mathrm{~kg} / \mathrm{m}^{3}$ to accommodate the water density change crossing the supercritical point.

\section{Preliminary Test of the Modifications}

The validation of the extended codes cannot be implemented without support of the related SCWR experiment, which 

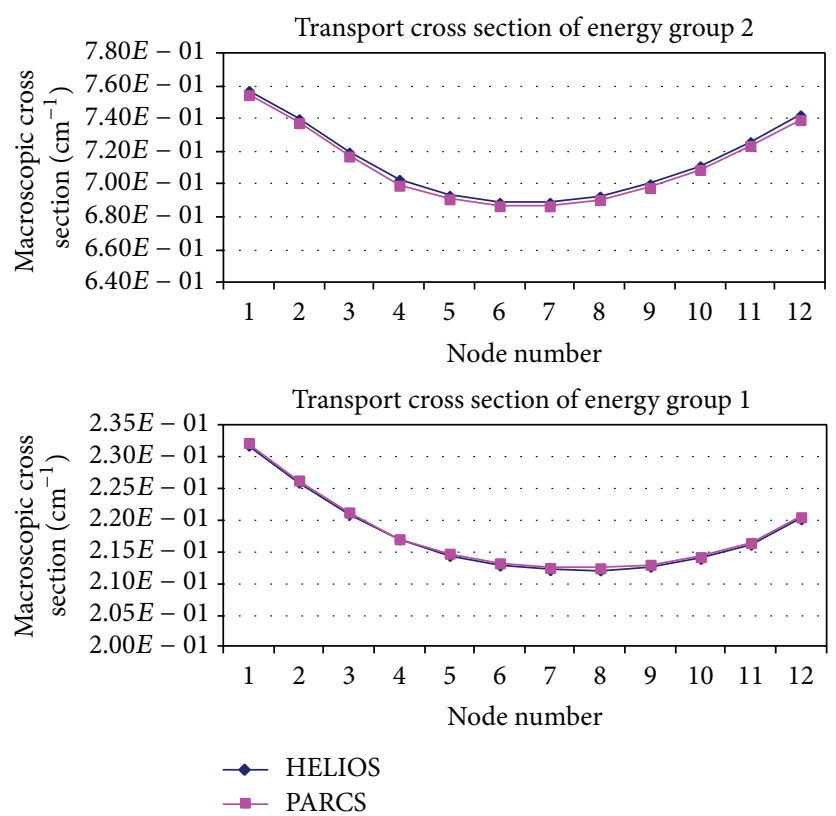

FIgURE 5: Comparison of cross sections from PARCS and HELIOS.

TABLE 4: Densities from coupled PARCS node and RELAP5 volumes.

\begin{tabular}{|c|c|c|c|c|}
\hline \multicolumn{3}{|c|}{ From Table 3 in mapping file } & \multicolumn{2}{|c|}{ Density $\left(\mathrm{kg} / \mathrm{m}^{3}\right)$} \\
\hline Hydraulic volume number & Node number & Weighting factor & RELAP5 & PARCS \\
\hline 753030000 & 274 & 1 & 659.84 & 659.8457 \\
\hline 753040000 & 475 & 1 & 660.53 & 660.5327 \\
\hline 753050000 & 676 & 1 & 663.39 & 663.3935 \\
\hline 753060000 & 877 & 1 & 668.55 & 668.5484 \\
\hline 753070000 & 1078 & 1 & 675.67 & 675.6677 \\
\hline 753080000 & 1279 & 1 & 684.22 & 684.2207 \\
\hline 753090000 & 1480 & 1 & 693.64 & 693.6387 \\
\hline 753100000 & 1681 & 1 & 703.33 & 703.3298 \\
\hline 753110000 & 1882 & 1 & 714.08 & 714.0801 \\
\hline 753120000 & 2083 & 1 & 726.54 & 726.5369 \\
\hline 753130000 & 2284 & 1 & 739.96 & 739.9585 \\
\hline 753140000 & 2485 & 1 & 754.07 & 754.0657 \\
\hline
\end{tabular}

is not available for this concept design. The verification of the extended codes could be done with the help of other verified SCWR-capable codes, which is not accessible currently. However, some preliminary tests presented here can help to confirm the new added functions in the modified codes for SCWR analysis working properly.

5.1. Cross Section Feedback Module. Current coupled PARCS uses PMAX files to supply nuclear cross section data generated by lattice code HELIOS. And the PMAX files are produced by the GenPMAXS code, which is an interface between lattice codes and PARCS and it already has the capability to generate the cross section data based on separated moderator and coolant channels [11]. According to the assembly geometry shown in Figure 3 and parameters in Table 2, macroscopic cross sections are calculated for the same assembly with PARCS and HELIOS, and the coolant and moderator thermal parameters in this test are shown in Table 3. A comparison of transport cross sections generated by PARCS using the modified cross section feedback module from PMAX file and transport cross sections produced directly by HELIOS in two energy groups are shown in Figure 5. The difference is acceptable considering that the interpolation of PMAX file data is used in PARCS module. The same comparisons are also accomplished successfully for absorption cross sections, fission cross sections, and capture cross sections of Xenon and Samarium.

5.2. Code Coupling Module. To confirm the coupled PARCS/RELAP5 is transporting the mapped moderator information correctly, a simple coupled SCWR calculation is carried out. A part of Table 3 of mapping file, which displays 


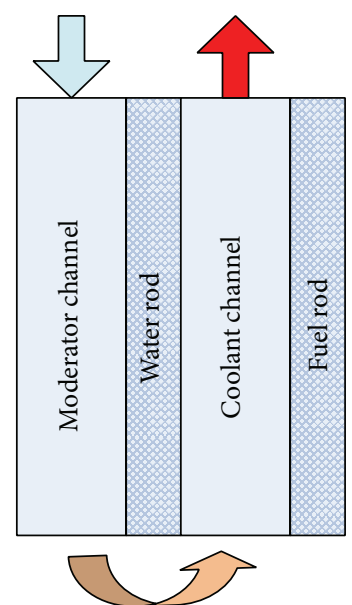

Figure 6: Flow path model of RELAP5 test.

the corresponding hydrodynamics volume and nodes in two codes and the coupling weighting factor, is shown in Table 4. The comparison of the moderator densities from PARCS and RELAP5 is also shown in Table 4. It shows the coupled hydrodynamic volumes in RELAP5 and nodes in PARCS are sharing the same moderator densities. The similar comparisons are also passed for moderator temperature, coolant temperature and density, fuel temperature, and power.

\subsection{RELAP5 Modification for Dealing with Supercritical} Pressure. The original RELAP5 failed in the middle of the calculation because of the escalation of the fluctuation both in pressure and temperature at supercritical pressure, while the modified RELAP5 calculated successfully with no fluctuation noticed. In order to demonstrate the capability of the modified RELAP5, a simplified test model in which two connecting pipes representing moderator channel and coolant channel with counter flowing heated water passing through are shown in Figure 6, and the moderator inlet pressure is increased linearly from $26 \mathrm{MPa}$ to $27.1 \mathrm{MPa}$, and coolant outlet pressure from $25.5 \mathrm{MPa}$ to $26.6 \mathrm{MPa}$ within 3000 seconds. The results are shown in Figure 7.

\section{Discussion}

The modifications in coupled codes PARCS/RELAP5 have been discussed and verified; the newly developed codes gained the capability simulating the separated moderator and coolant flow channel, simulating supercritical water beyond supercritical point and getting neutronics feedback from separated moderator. The coupled codes have been applied to analyze SCWR [12]; a moderator flow reversal has been found during burnup and transient cases, and because the separated highest power channel and highest cladding surface temperature channel, the maximum cladding temperature is lower than previous cases.

For other transients such as LOCA, in which large pressure excursion exists, the current modification is not
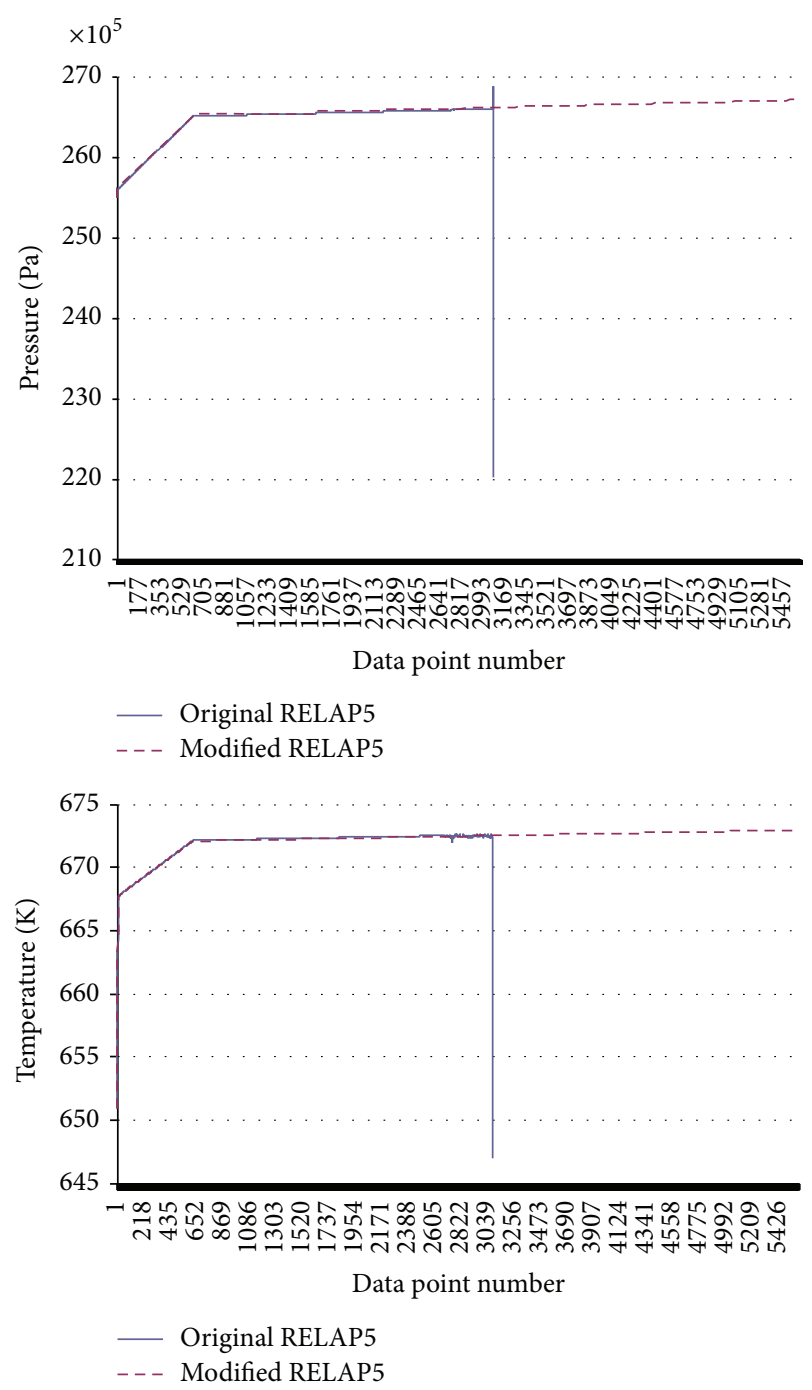

FIgURE 7: Pressure and temperature from test case with original and modified RELAP5.

enough to study the related system behavior. It is because the large depressurization in those transients introduces the complicated heat transfer and flow dynamics phenomena crossing pseudocritical point; sometimes a two-phase flow, further investigation to establish appropriate model based on realistic experiment data is needed, such as how to define the void fraction while crossing the pseudocritical point.

\section{Nomenclature}

$\begin{array}{ll}V: & \text { Volume }\left(\mathrm{m}^{3}\right) \\ D: & \text { Density }\left(\mathrm{kg} / \mathrm{m}^{3}\right) \\ T: & \text { Temperature }\left({ }^{\circ} \mathrm{C}\right) \\ \Sigma: & \text { Macroscopic cross section }\left(\mathrm{m}^{-1}\right) \\ \eta: & \text { Bypass ratio } \\ \alpha: & \text { control rod insertion } \\ M: & \text { Moderator } \\ c: & \text { Coolant } \\ f: & \text { Fuel. }\end{array}$




\section{Conflict of Interests}

The authors declare that there is no conflict of interests regarding the publication of this paper.

\section{Acknowledgments}

The authors would like to thank the flowing sponsors, Grants no. DE-FG03-01SF22328 and 2401-UW-DOE-4423 from the Department of Energy of U.S, Project 11205098 supported by National Natural Science Foundation of China, and Project 20100073120049 supported by Ministry of Education of China.

\section{References}

[1] J. Starflinger, N. Aksan, D. Bittermann et al., "Roadmap for supercritical-water-cooled reactor R\&D in Europe," in Proceedings of the Atoms for Prosperity: Updating Eisenhower's Global Vision for Nuclear Energy (GLOBAL '03), pp. 1137-1142, New Orleans, La, USA, November 2003.

[2] J. Buongiorno and P. E. Macdonald, "Progress report for the FY-03 generation-IV R\&D activities for the development of the SCWR in the U.S.," Tech. Rep. INEEL/EXT-03-01210, Idaho National Engineering and Environmental Laboratory, 2003.

[3] C. B. Cliff, J. Buongiorno, and P. E. Macdonald, "A parametric study of the thermal-hydraulic response of supercritical light water reactors during loss-of-feedwater and turbinetrip events," in Proceedings of the International Conference on Advanced Nuclear Power Plants and Global Environment (ANP/GENES4 '03), Kyoto, Japan, 2003, paper no. 1009.

[4] A. Bousbia-Slah, J. Vedovi, F. D’Auria, and K. Ivanov, "Analysis of the peach bottom 2 turbine trip 2 experiment by coupled RELAP5-PARCS there-dimensional codes," Nuclear Science and Engineering, vol. 148, no. 2, pp. 337-353, 2004.

[5] P. O. Hu and P. P. H. Wilson, "Supercritical water reactor steady-state, burnup, and transient analyses with extended PARCS/RELAP5," Nuclear Technology, vol. 172, no. 2, pp. 143$156,2010$.

[6] T. Downar, D. Lee, Y. Xu, T. Kozlowski, and J. Staudenmier, PARCS v2.6 U.S. NRC Core Neutronics Simulator USER MANUAL Draft (11/10/04), Purdue University and NRC, 2004.

[7] Nuclear Safety Division, RELAP5/MOD3.3 Code Manual, Information System Laboratories, 2004.

[8] C. B. Davis, J. Buongiorno, and P. E. Macdonald, "A parametric study of the thermal-hydraulic response of supercritical light water reactors during loss-of-feedwater and turbine-trip events," in Proceedings of the International Conference on Advanced Nuclear Power Plants and Global Environment (ANP/ GENES4 '03), Kyoto, Japan, 2003, paper no. 1009.

[9] L. Haar, J. S. Gallagher, and G. S. Kell, NBS/NRC Steam Tables, Hemisphere Publishing Corporation, McGraw-Hill, New York, NY, USA, 1984.

[10] http://www.specialmetals.com/documents/Incoloy\%20alloy\% 20MA956.pdf.

[11] Y. Xu and T. Downar, GenPAMXS Manual, Purdue University, 2005.
[12] P. Hu and P. Wilson, "Supercritical water reactor steady state, burnup and transient analysis with extended PARCS/RELAP5," in Proceedings of the 4th International Symposium on Supercritical Water-Cooled Reactors, Heidelberg, Germany, 2009, paper no. 13. 


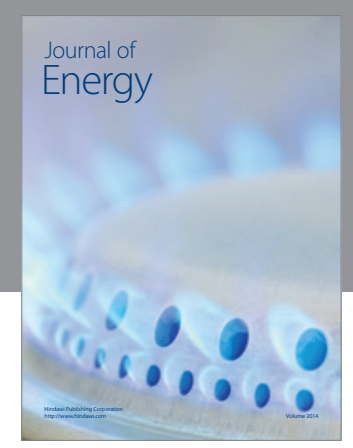

Journal of

Industrial Engineering
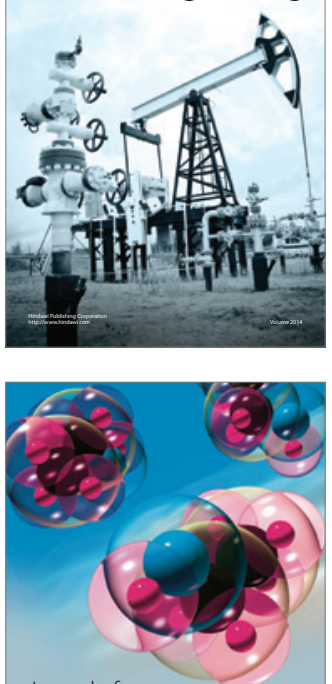

Fuels
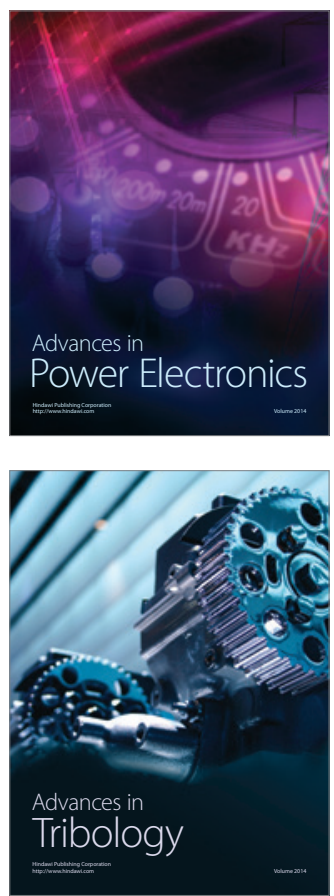

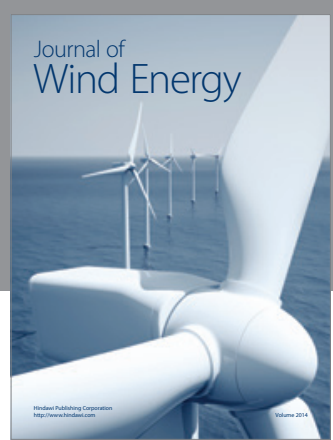

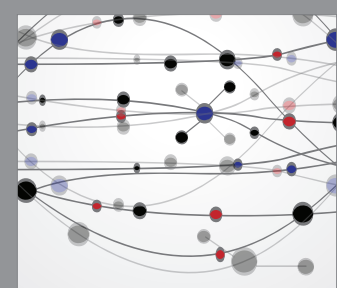

The Scientific World Journal

Submit your manuscripts at http://www.hindawi.com

Journal of

Structures
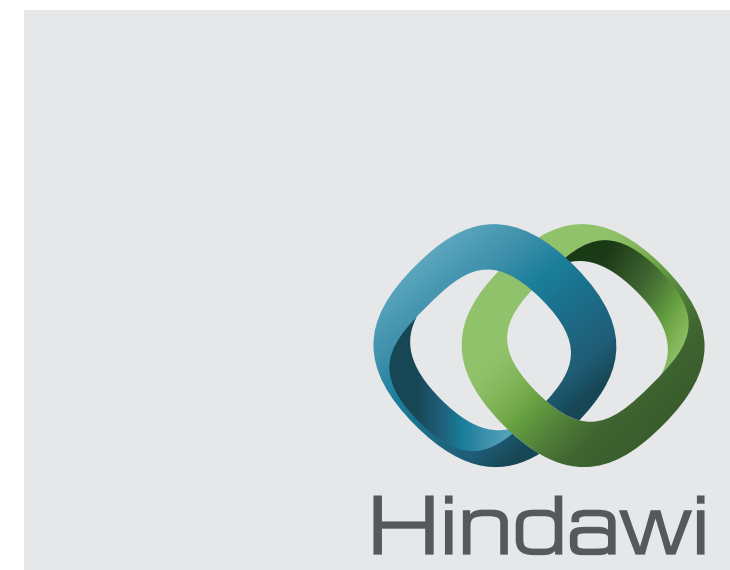

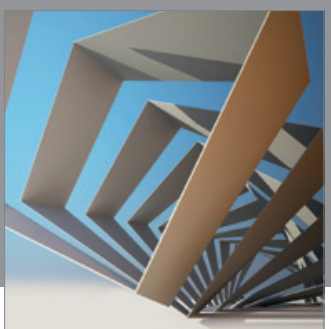

Rotating

Machinery
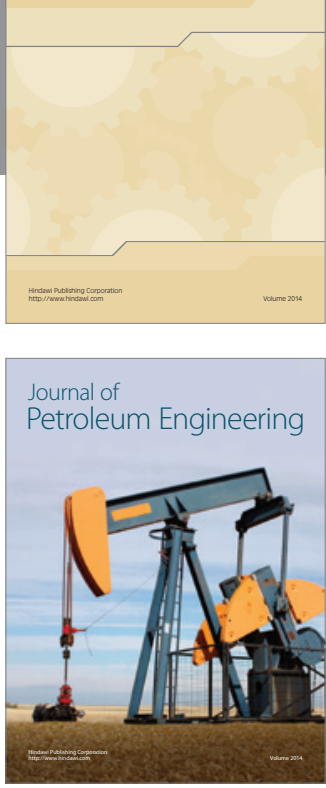

Journal of

Solar Energy
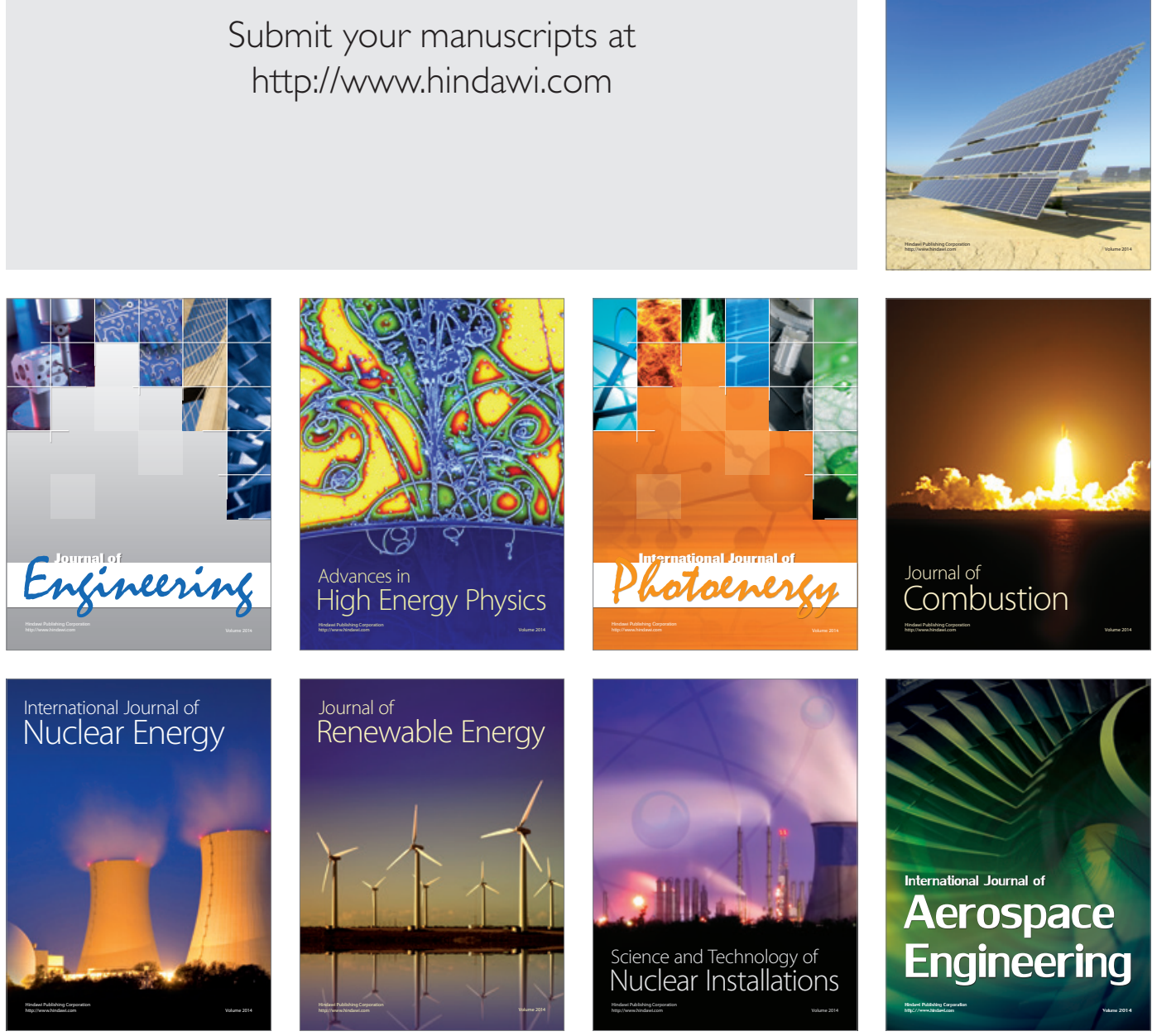